\title{
CHILD AND MOTHER PLAY IN SOUTH KOREA: A LONGITUDINAL STUDY ACROSS THE SECOND YEAR OF LIFE
}

\author{
Keumjoo KWAK ${ }^{1)}$, \\ ${ }^{1)}$ Seoul National University, Korea \\ Diane L. PUTNICK ${ }^{2)}$ and Marc H. BORNSTEIN ${ }^{2)}$ \\ ${ }^{2)}$ National Institutes of Health, U.S.A.
}

\begin{abstract}
Play is a predominant individual and social activity of early childhood and has been related to young children's early cognitive growth, social development, and preparation for formal schooling. We examined individual differences and developmental changes in South Korean child and mother exploratory and symbolic play longitudinally when children were 13 and 20 months of age. Children engaged in less exploratory and more symbolic play when playing collaboratively with their mothers than when playing alone. Children engaged in more symbolic play at 20 months than 13 months. Child solitary and collaborative symbolic play were modestly stable across time, but child exploratory play and maternal play were not. Child solitary and collaborative symbolic play were correlated across the two ages. Child and mother play were regularly associated at the two ages, and 13-month maternal play predicted 20 -month child collaborative play. The cross-cultural validity of play is affirmed, and individual differences and age-related changes in child and mother play are partly mediated by matched partner play and partly motivated by processes independent of partner play.
\end{abstract}

Key words: Korea, play, mother-infant interaction

\section{Child and Mother Play}

Over the course of the second year, children are increasingly able to conceptualize abstract relations between symbols and their real-world referents. This fundamental change in representational ability is reflected in a range of newly emerging symbolic competencies, a noteworthy one being play. In the first year, play is predominantly characterized by sensorimotor manipulation where the goals of child play are to extract information about objects, what objects do, what perceivable qualities objects have, and what immediate effects objects produce. Play is first directed functionally towards a single object (e.g., throwing a ball) and later incorporates combinations of two or more objects inappropriately or appropriately (e.g., juxtaposing a nesting barrel with a telephone, and later inserting one barrel into its appropriate partner barrel). This type of

\footnotetext{
We thank Y. Choi, Y. Kim, and K. Painter. This research was supported by the Intramural Research Program of the NIH, NICHD.

Correspondence concerning this article should be addressed to Marc H. Bornstein, Child and Family Research, National Institute of Child Health and Human Development, National Institutes of Health, Suite 8030, 6705 Rockledge Drive, Bethesda MD 20892-7971, U.S.A. (e-mail: Marc_H_Bornstein@nih.gov)
} 
play is commonly referred to as "exploratory" because children's actions are tied to the tangible properties of objects. In the second year of life, children's play takes on a representational "nonliteral" or "as if" quality. The goal of play now appears to be "symbolic," to represent experience. Symbolic play repertoires include simple pretense about self (e.g., pretending to drink from an empty toy cup) and about others (e.g., putting a doll to sleep), as well as sequences of pretense (e.g., pouring into an empty cup and then pretending to drink), and they even include substitutions (e.g., pretending to talk into a block as though it were a cellular telephone). In short, play reflects a salient everyday venue for the expression of both exploratory action and symbolic thinking in the young child (Bornstein, 2006; Bornstein \& O'Reilly, 1993; Rubin, Fein, \& Vandenberg, 1983; Tamis-LeMonda \& Bornstein, 1996).

These developmentally regular processes notwithstanding, variability in play among children of the same age is common (e.g., Bornstein, Haynes, O’Reilly, \& Painter, 1996), and that variability is thought to reflect, at least in part, differences in children's maturing cognitions and behaviors as mediated by their more mature partners' play (e.g., Bornstein et al., 1996; Užgiris \& Raeff, 1995; Vygotsky, 1978). Play is a situation where parents provide children with diverse and pleasant experiences organized to cultivate and practice abilities that promote children's adaptation to the physical and social world. Children initiate play sequences, but they also learn from and imitate the play they see (e.g., Užgiris, Benson, Kruper, \& Vasek, 1989) and they complete play scenarios begun or supported by others (e.g., Dunn \& Wooding, 1977).

Indeed, many different roles in shaping children's play are open to adult play partners: Some mothers adjust the level of their play to advance their children's play, and mothers who are more knowledgeable about the development of child play engage their children in more sophisticated play (Damast, Tamis-LeMonda, \& Bornstein, 1996; TamisLeMonda, Chen, \& Bornstein, 1998). In consequence, child collaborative play is normally more sustained, more complex, and more diverse than is their solitary play. For example, O'Connell and Bretherton (1984) observed that children engaged in a greater number of different symbolic activities when in collaborative as opposed to solitary independent play. Fiese (1990) showed that children spent a greater percentage of time in symbolic play, as opposed to exploratory play, during mother-child play compared to child-alone play. Bornstein et al. (1996) likewise reported that the degree to which mothers participated in and guided their children's symbolic play affected the level of their children's symbolic play: Children engaged in symbolic play more and for longer periods when in collaboration than when alone, and in collaborative play the proportion of child play that was symbolic increased from circumstances where children initiated play to ones where their mothers initiated play. These kinds of results provide support for the hypothesis that social interaction enhances symbolic development. As a novice symbolic player, the child benefits from the presence and activities of a more experienced play partner. Against a backdrop of universal tendencies in the development of children's play, empirical investigation has revealed strong experiential dyadic effects.

Although there is widespread agreement that maternal activities fundamentally guide children's play and learning, still little effort has been expended toward detailing specific 
actions of mothers that affect children's play. Codes for maternal play would address this end and permit a characterization of patterns, processes, and determinants of early play development and promote direct comparisons between child and mother. For the present study, we therefore employed a common coding system for child and mother play, and we assessed variability in children's play and variability in mothers' demonstrating and soliciting children's play at two ages, 13 and 20 months.

\section{Play in South Korean Children and Mothers}

As described, the growth of play in early childhood is thought to follow some pervasive and possibly universal developmental processes. Empirical studies of child object play suggest that the normative developmental trajectory is widespread and may be maturational and progressive in nature. However, the developmental literature is almost wholly based on Western samples. Although it has underwritten considerable progress in describing the development of play, monocultural research has also incurred the unintended consequence of restricting a broader understanding of play. Absent a culturally comparative perspective, it is not possible to distinguish developmental characteristics that may be universal from those that may be specific to culture (e.g., Bornstein, 1980, 1991, 1995; Kennedy, Scheirer, \& Rogers, 1984; Moghaddam, 1987; Russell, 1984). What little cross-cultural research on play that exists shows that specific structures associated with general processes are modifiable in some degree with experience.

Cultural variation in social conventions, communication styles, and construals of the self can be expected to influence the nature of individual experience, social behavior, and self-expression in development as well as how children engage in social interactions. For these reasons, we studied the development of play in South Korea. More specifically, we asked, what path does the development of play in South Korean children follow? How do Korean mothers engage their children in play? What characteristics of Korean culture likely affect Korean child and mother play? We expected young children in South Korea to engage in exploratory as well as symbolic play, but we also expected children and their mothers to engage in symbolic play more than exploratory play as they grow because of certain indigenous Korean cultural traditions and expectations.

Korean values emphasize group harmony and cooperation and may influence children's symbolic play. Although sweeping social changes have recently occurred in South Korea, families tend to retain values inherited from the country's Confucian traditions and customs which bear on their childrearing practices, parent-child relationships, and children's development and behaviors (Kim, 1995; Park \& Cho, 1995). For example, identification with the collective is strong, and social relationships continue to be based on a hierarchy of status differences reflecting age, role, and gender (Min, 1995; Park \& Cho, 1995).

The Korean interdependent view of the self is generally expressed in a collectivist orientation. Jeong, the affective bond uniting Korean families and social groups, is associated with being attentive to others' needs, attempting to "read" their minds, and maintaining harmonious shared experiences (Choi, Kim, \& Choi, 1993). In an empirical 
study examining the psychological connotations of "me" among Korean respondents, Maday and Szalay (1976) found that Koreans actually emphasized relatedness and interdependence among individuals, or the "we." In addition, the Confucian heritage in Korea places an extremely high value on education and exerts considerable societal pressure for academic achievement (Kim \& Park, 2003). In Korea, academic success is considered not just as a means for personal achievement but also as a way to fulfill obligations to one's family and to the larger society.

We concentrate in this study on mother-child play as a forum for the early expression of such cultural conventions. Mothers are children's main companions in the play setting until about 2 years, and mothers generally lead young children in play. Therefore, studies that relate maternal and infant play form a prominent context of their interaction. Moon (1996) studied pretend play in 20- to 35-month-old South Koreans according to their age and sex, to the age and sex of their play with peers, and to their mothers' availability. She examined relations between the level of pretend play in children and maternal play eliciting strategies in interactive play in each of three age intervals $(20-26,27-30,31-35$ months). Children's level of pretend solitary play increased with age, as did their level of pretend in peer play. However, significant negative correlations emerged between children's level of pretend play and mothers' physical play strategies. Kim and Lee (2003) studied early pretense in children from 19 to 48 months of age. They found that symbolic levels of pretense increased with age, but they did not find sex differences. Bae et al. (2004) adapted a pretend play checklist and asked mothers to estimate child play in infants aged 9 to 11 months and 16 to 24 months, along with mothers of infants aged 9 to 36 months. Functional and pretend play, and the symbolic level of play, all reportedly increased with age. Girls also reportedly showed higher competence in pretend play than boys. Children's pretend play and parents' reported participation in play with their children were also correlated, and maternal participation reportedly contributed to higher child scores in pretend play. Although informative, studies to date have relied exclusively on mothers' (sometimes retrospective) reports, have mostly enlisted small sample sizes, have not been longitudinal, and have not systematically addressed the gender question. Here we redressed those experimental shortcomings.

\section{Gender and Play}

Infant gender is a variable that relates to representation, language, and play. However, two different results have emerged in Korean studies about gender and play. On the one hand, Moon (1996) and Kim and Lee (2003) reported no effect of sex in child alone play for 20- to 35-month-olds. On the other hand, Bae et al. (2004) reported that girls showed higher pretend play competence than boys, the gender difference that is also often found in many Western studies (e.g., Bornstein et al., 1996).

\section{Continuity and Stability in Play}

Developmental research is directed in the main to assess average performance across time and variation about the average. We use the term continuity to describe consistency in the absolute level of play in a group through time. For example, continuous play is 
displayed by a group of children or adults at (statistically) the same level at one point in time and at a second point later in time. Discontinuous play in a group of children or adults increases or decreases in mean level over time. We use the term stability to describe consistency in the relative ranks of individuals in a group with respect to play through time. For example, stability in child or adult play occurs when some individuals play at relatively high levels at one point in time and again play at relatively high levels at a second point later in time, where other children or adults play at lower levels at both times. Developmentally unstable play occurs when children and adults do not maintain their relative order.

Continuity in a group and stability in individuals are conceptually and statistically independent (Bornstein, Brown, \& Slater, 1996). For example, continuity-and-stability describes the situation where the mean group level remains the same over time and individuals in the group retain their relative standing over time. However, the mean group level could change over time (increase or decrease), but individuals in the group remain consistent in their relative standing: discontinuity-and-stability. And so forth, for continuity-and-instability and for discontinuity-and-instability.

\section{The Present Study}

This prospective longitudinal study examined multiple aspects of play in South Korean children and mothers over a 7-month period in the second year. We addressed 5 main questions: We assessed (1) the continuity of child play across child age (13 to 20 months) and play setting (solitary to collaborative); (2) the continuity of maternal play across child age; (3) the stability of child and maternal play across child age; (4) associations between solitary and collaborative play in children; and (5) concurrent associations between child play and maternal play as well as predictive associations from 13-month maternal play to 20 -month child play, and 13 -month child play to 20 -month maternal play. In analyses of play change over time, we partialed maternal play from child play, and child play from maternal play, to assess play development independent of partner activity. Likewise, in assessing predictive influences, we partialed concurrent play so that unique predictions from mother to child, and from child to mother, could be examined. Finally, in all of these analyses we paid special attention to child gender.

\section{METHOD}

Sample

Altogether, 44 South Korean mothers and their firstborn children, 22 boys and 22 girls, were observed twice, once when the child was 13 months and again when the child was 20 months. Mothers were recruited from greater metropolitan Seoul through mass mailing and advertisements in hospitals. On average, mothers were 29.69 years $(S D=2.35)$ at the first visit and $30.27(S D=2.37)$ at the second visit. Families were of middle to upper SES on the Hollingshead (1975) Four-Factor Index of Social Status (see Bornstein, Hahn, Suwalsky, \& Haynes, 2003), $M=50.29, S D=6.34$. Mothers' average educational level (measured from the 7-point Hollingshead scale) was $5.77, S D=.81$; on average, mothers had earned a university degree. Approximately $50 \%$ of mothers were working outside of the home at both visits, and for those mothers the mean numbers of hours of employment were $M \mathrm{~s}=43.02$ and $36.34, S D \mathrm{~s}=13.12$ and 16.94 , respectively, at 
the 13 - and 20-month visits.

All children were born at term and had been healthy since birth, excluding minor illness. Children averaged 12.91 months $(S D=.24)$ at the first visit and 19.99 months $(S D=.17)$ at the second visit. We recruited a sample balanced with respect to sex of child so that potential differences between girls and boys, and between mothers of girls and mothers of boys, could be examined (Fagot, 1995; Leaper, 2002). Dyads were observed in the second year because this is typically a time when children still engage in exploratory play but also symbolically represent everyday experiences of self and others in their play. In the second year, children conceptualize abstract relations between symbols and their real-world referents, and play (and language) has emerged as a significant mode of representation and basis of interaction, but children are thought to vary considerably among themselves in these abilities (Bornstein et al., 1996; Tamis-LeMonda, Užgiris, \& Bornstein, 2002). The second-year child is also sensitive and responsive to maternal expressions of feelings and emotions, and by this age children can interpret the physical and psychological states of others and also experience those states affectively (Edwards \& Liu, 2002). Furthermore, we wanted to study mothers who were settled in the maternal role and whose views and parenting had had ample opportunity to stabilize. In consequence, 1-2 years postpartum appeared to constitute a formative time to investigate variation in child development and in parenting.

\section{Procedures}

Overall design. At both time points, children and mothers were observed in the home during one 2-hr visit by one South Korean female researcher. Mothers had been instructed that the researcher was interested in children's cognitive and social skills development. During the visit, child (a) solitary and (b) collaborative play with mother were audio/videorecorded from which measures of child and mother exploratory and symbolic play were derived, and an inventory of sociodemographic information about the family completed.

Child and mother exploratory and symbolic play. Each visit began with a set up and familiarization period, lasting approximately 20 to $30 \mathrm{~min}$ (Stevenson, Leavitt, Roach, Chapman, \& Miller, 1986), and audio/ videorecording of two consecutive 10-min play episodes commenced when the mother and child were at ease. The findings of previous studies using 10-min observations of play lend credence to the validity of these temporal parameters (see Bornstein et al., 1996). First, the child was filmed in solitary play while the mother and the researcher sat nearby but did not interact with the child. Minutes afterward, the child and mother played collaboratively. The mother was asked to play with her child as she ordinarily would do and to disregard the researcher's presence as much as possible. A set of standard, age-appropriate toys (doll, blanket, tea set, toy telephone, toy train, two small picture books, foam ball, and set of nesting barrels) was used for both play sessions; these toys were selected to represent feminine, masculine, and gender-neutral categories, and allowed for a variety of different play behaviors ranging from simple exploration to relatively complex symbolic play (Belsky \& Most, 1981; Bornstein et al., 1996; Caldera, Huston, \& O’Brien, 1989; McCune-Nicolich \& Fenson, 1984). Mothers and children could use any or all of the toys provided; the child's own toys were not present.

In demonstrating play, a mother provides her child with information about how to engage in particular activities by modeling the actions herself (e.g., mother dials the telephone); in soliciting play, a mother places the onus for play on her child by encouraging the child to engage in a play activity (e.g., mother moves the telephone toward her child while suggesting that the child dial the telephone).

Child solitary play was coded from the audio/videorecords of the solitary play session, and child collaborative play and maternal demonstrations and solicitations of play were coded from the audio/ videorecords of the collaborative play session. All play was coded in accordance with a mutually exclusive and exhaustive category system that included 8 levels and a default (no play) category; these play levels were derived from previous research on the progressive nature of play across the first and second years of life (see Bornstein et al., 1996; Tamis-LeMonda \& Bornstein, 1996; Vibbert \& Bornstein, 1989). Play level 1: Unitary functional activity focused on the production of effects that were unique to a single object (e.g., pulling a toy train). 2: Inappropriate combinatorial activity included the inappropriate juxtaposition of two or more objects (e.g., putting the ball in the telephone). 3: Appropriate combinatorial activity included the appropriate juxtaposition of two or more objects (e.g., nesting the barrels). 4: Transitional play approximated pretense but without confirmatory evidence (e.g., putting a telephone handset to the ear without vocalizing). 5: Selfdirected pretense consisted of pretense activity directed toward self (e.g., drinking from the empty toy cup). 6: Other-directed pretense consisted of pretense activity directed towards someone or something else (e.g., putting the doll to sleep). 7: Sequential pretense included linking two or more pretense actions (e.g., pouring 
into the empty cup from the teapot and then drinking). 8: Substitution pretense involved one or more object substitutions (e.g., pretending a cup is a telephone and talking into it). Play was coded continuously by noting the play level as well as start and end times (accurate to $1 \mathrm{sec}$ ). Minimum play time was set to $1 \mathrm{sec}$, and play at a given level was coded so long as there was no break longer than $10 \mathrm{sec}$ and the player did not touch another toy.

Scores for Levels 1-4 were summed to form measures of the frequency and duration of exploratory play, and scores for Levels 5-8 were summed to form measures of the frequency and duration of symbolic play. For child solitary play, child collaborative play, and maternal demonstrations of play, four indices of exploratory and symbolic play were developed: the count of play bouts that were exploratory or symbolic, the proportion of play bouts that were exploratory or symbolic, the total durations of exploratory and symbolic play, and the proportions of play duration that were exploratory or symbolic. In previous samples and in the current data set, these indices were consistently highly correlated (Bornstein et al., 1996; Bornstein, Haynes, Legler, O'Reilly, \& Painter, 1997), and so single measures of the amounts of exploratory and of symbolic play, absolutely and proportionally and with respect to both frequency and duration, were calculated as mean standard scores $(M=0, S D=1)$ of the four indices. For maternal solicitations of play, two indices of play were used: the count of play bouts which were exploratory or symbolic and the proportion of play bouts which were exploratory or symbolic. On average, both children and mothers engaged in play in $45 \%$ or less of the observational period; therefore, aggregated scores for exploratory play and symbolic play were not structurally determined to be inversely related.

Reliability for child solitary and collaborative play and maternal demonstrations of play was based on sec-by-sec agreement. There were $600 \mathrm{sec}$ in each play session, and kappa ( $\kappa)$ was based on whether the coders agreed with the play level coded for each sec. Two coders were natives of South Korea; each first trained to reliability on consensus coding. Reliability $(\kappa)$ was .66 for child play and .68 for maternal play. Then, because of the level of reliability, the two coders scored all tapes by consensus.

Evaluation of play sessions. To assure that mothers' and children's behaviors were representative of their usual behavior, and as a check against threats to validity, at the conclusion of the home visit the mother evaluated mother-child interaction in the observation by marking a series of 8-point (range $=0$ to 7) graphic rating scales, randomly ordered with respect to valence but recoded in ascending order so that $0=$ Not at all and 7 = Very much so. We evaluated four characteristics of the play session from the perspective of mothers: their children's health status, the typicality of their children's and their own play, and their own comfort level during the session. At both the 13- and 20-month visits, mothers reported that the children were in good health $\left(M_{13}=5.39, S D_{13}=2.20, M_{20}=5.34, S D_{20}=1.68, t(37)=.13, n s\right)$, that their children's play $\left(M_{13}=4.95, S D_{13}=2.16, M_{20}=4.50, S D_{20}=2.14, t(37)=.91, n s\right)$ and their own play $\left(M_{13}=5.68\right.$, $\left.S D_{13}=1.89, M_{20}=5.32, S D_{20}=1.79, t(37)=.87, n s\right)$ were typical, and that their level of comfort was high $\left(M_{13}=5.50, S D_{13}=1.98, M_{20}=5.42, S D_{20}=1.48, t(37)=.20, n s\right)$. These data suggest that our procedures yielded results that are broadly generalizable and did not differ from 13 to 20 months.

\section{RESUlTS AND DisCUSSION}

\section{Preliminary Analyses, Analytic Strategy, and Statistical Controls}

Prior to any analysis, univariate distributions of play variables and potential covariates were checked by age wave for normalcy, homogeneity of variance, and outliers (Tukey, 1977). No transformations were necessary, and examination of the distributions showed no univariate outliers.

Following these preliminary analyses, repeated-measures linear mixed models were computed on child and mother play to assess changes in mean level across time. Next, correlations among child and between mother and child play were computed. In all analyses, we controlled maternal education and hours of employment because they were presumed to be related to play behavior. Furthermore, we controlled partner play behavior in all predictive and mean-level analyses. 
Table 1. Descriptive Statistics of Child and Mother Play and Correlations Between 13- and 20-months

\begin{tabular}{|c|c|c|c|c|c|c|}
\hline & \multicolumn{2}{|c|}{13 months } & \multicolumn{2}{|c|}{20 months } & \multirow{2}{*}{$r$} & \multirow{2}{*}{$r_{p}$} \\
\hline & $M$ & $S D$ & $M$ & $S D$ & & \\
\hline \multicolumn{7}{|c|}{ Child Solitary Play } \\
\hline Exploratory & .23 & .82 & .10 & .81 & .02 & -.02 \\
\hline Symbolic & -.47 & .80 & -.00 & .92 & $.39 * *$ & $.34 *$ \\
\hline \multicolumn{7}{|c|}{ Child Collaborative Play } \\
\hline Exploratory & -.10 & .76 & -.23 & .82 & .25 & .09 \\
\hline Symbolic & .08 & .77 & .39 & .84 & $.32 *$ & .18 \\
\hline \multicolumn{7}{|c|}{ Maternal Demonstrations } \\
\hline Exploratory & .06 & .82 & -.06 & .84 & .21 & -.17 \\
\hline Symbolic & .07 & .79 & -.07 & .85 & $.29 *$ & .08 \\
\hline \multicolumn{7}{|c|}{ Maternal Solicitations } \\
\hline Exploratory & -.07 & .84 & .07 & .95 & .17 & .09 \\
\hline Symbolic & -.16 & .84 & .16 & .85 & .11 & -.18 \\
\hline
\end{tabular}

Note. $\quad r=$ zero-order stability coefficients, and $r_{p}=$ partial stability coefficients, controlling for maternal education, hours of employment, and partner play behavior.

$* p \leq .05 . * * p \leq .01$. (one-tailed).

\section{Child Play across Time, Play Setting, and Gender}

Table 1 shows descriptive statistics of child play at 13 and 20 months. In answer to our first question about the continuity of child exploratory and symbolic play across child age and play setting, two linear mixed models were conducted. Child age (13 vs. 20 months) and play setting (solitary vs. collaborative) were within-subjects repeated factors and child gender (girls vs. boys) was a between-subjects factor. Maternal education, hours of employment, and demonstrations and solicitations of symbolic and exploratory play were entered into the model as fixed-effect covariates. For exploratory child play, no twoway or three-way interactions were significant, and main effects for child age and gender were nonsignificant, $F(1,141.23)=.00, n s$, and $F(1,37.30)=.00, n s$, respectively. A main effect emerged for play setting, $F(1,113.84)=8.87, p \leq .01$ : Collapsing over time, children engaged in more exploratory play while alone than with their mothers. For symbolic child play, again no two-way or three-way interactions were significant, nor was the main effect for gender. There were significant main effects for child age, $F(1$, $140.83)=8.20, p \leq .01$, and play setting, $F(1,109.58)=21.29, p \leq .001$ : Collapsing over play settings, children engaged in more symbolic play at 20 months than at 13 months. Furthermore, collapsing over time, children engaged in more symbolic play when playing collaboratively with their mothers than when playing alone. 


\section{Mother Play across Time and Gender}

To answer our second question about the continuity of maternal demonstrations and solicitations of exploratory and symbolic play across child age, four linear mixed models were conducted for child age (a repeated within-subjects effect) and child gender (between-subjects) on the four maternal dependent variables-demonstrations and solicitations of exploratory and symbolic play (see Table 1 for descriptive statistics). Maternal education, hours of employment, and child collaborative exploratory and symbolic play were entered into the model as fixed-effect covariates. No main effects or interactions were significant for maternal demonstrations of exploratory play. For maternal demonstrations of symbolic play, a significant main effect of child age emerged, $F(1,44.78)=4.52, p \leq .05$ : Controlling for child play, mothers demonstrated more symbolic play to their children when they were 13 months than when they were 20 months. For maternal solicitations of exploratory play, only the Child Age by Gender interaction was significant, $F(1,40.74)=4.97, p \leq .05$ : At 13 months mothers solicited more exploratory play from boys, and at 20 months mothers solicited more exploratory play from girls, although neither of these effects was statistically significant. Finally, for maternal solicitations of symbolic play, no main effects or interactions were significant.

\section{Stability of Child and Mother Play across Time}

In answer to our third question about the stability of child and maternal play across child age, the ' $r$ ' column in Table 1 displays the zero-order stability coefficients for child and mother play. Child solitary and collaborative symbolic play and maternal symbolic demonstrations were modestly stable across time. The final column of Table 1 displays the partial correlations of 13 -month with 20 -month child and mother play controlling for maternal education, hours of employment, and partner play. After exercising these controls, only child solitary symbolic play was modestly stable across time.

\section{Associations between Solitary and Collaborative Play}

In answer to our fourth question about the associations between child solitary and collaborative play, we computed partial correlations between child solitary and collaborative play, controlling maternal education and hours of employment. Child exploratory play across contexts was not significantly correlated. At both time points, however, child solitary and collaborative symbolic play were moderately correlated, $r=.36, p \leq .05$, at 13 months and $r=.31, p \leq .05$, at 20 months.

\section{Concurrent and Predictive Mother-Child Associations}

In answer to our fifth question about the concurrent and predictive associations between maternal and child play, we computed partial correlations.

Concurrent. Partial correlations of child exploratory and symbolic play with maternal exploratory and symbolic play within each age, controlling maternal education and hours of employment, appear in Table 2. At both time points, correlations between child solitary exploratory and symbolic play with maternal demonstrations and solicitations of exploratory and symbolic play in the collaborative play session were 
Table 2. Partial Correlations Between Child and Mother Play at 13 and 20 months

\begin{tabular}{|c|c|c|c|c|c|c|c|c|}
\hline & \multicolumn{4}{|c|}{ Child Solitary Play } & \multicolumn{4}{|c|}{ Child Collaborative Play } \\
\hline & \multicolumn{2}{|c|}{ Exploratory } & \multicolumn{2}{|c|}{ Symbolic } & \multicolumn{2}{|c|}{ Exploratory } & \multicolumn{2}{|c|}{ Symbolic } \\
\hline & 13 months & 20 months & 13 months & 20 months & 13 months & 20 months & 13 months & 20 months \\
\hline \multicolumn{9}{|c|}{ Maternal Demonstrations } \\
\hline Exploratory & .06 & .20 & -.10 & -.20 & $.39 * *$ & $.57 * * *$ & $-.37 *$ & $-.60 * * *$ \\
\hline Symbolic & .08 & -.06 & -.02 & .08 & $-.37^{*}$ & $-.57 * * *$ & $.36^{*}$ & $.62 * * *$ \\
\hline \multicolumn{9}{|c|}{ Maternal Solicitations } \\
\hline Exploratory & -.10 & .15 & -.16 & -.07 & $.54 * * *$ & $.46^{* *}$ & $-.55 * * *$ & $-.39 *$ \\
\hline Symbolic & .10 & -.14 & .10 & .05 & $-.54 * * *$ & $-.67 * * *$ & $.56 * * *$ & $.61^{* * *}$ \\
\hline
\end{tabular}

Note. Correlations are controlling maternal education and hours of employment. $* p \leq .05 . * * p \leq .01 . * * * p \leq .001$.

Table 3. Partial Correlations Between Mother Play at 13 Months and Child Play at 20 Months

\begin{tabular}{|c|c|c|c|c|}
\hline \multirow{3}{*}{13 months } & \multicolumn{4}{|c|}{20 months } \\
\hline & \multicolumn{2}{|c|}{ Child Solitary Play } & \multicolumn{2}{|c|}{ Child Collaborative Play } \\
\hline & Exploratory & Symbolic & Exploratory & Symbolic \\
\hline \multicolumn{5}{|c|}{ Maternal Demonstrations } \\
\hline Exploratory & -.18 & -.00 & $.53 * * *$ & $-.50 * * *$ \\
\hline Symbolic & $.39 *$ & -.03 & -.30 & .29 \\
\hline \multicolumn{5}{|c|}{ Maternal Solicitations } \\
\hline Exploratory & .00 & -.19 & .27 & -.30 \\
\hline Symbolic & .01 & .20 & $-.43 * *$ & $.37 *$ \\
\hline
\end{tabular}

Note. Correlations are controlling for maternal education, hours of employment, and corresponding 20month maternal play behavior.

$* p \leq .05 . * * p \leq .01 . * * * p \leq .001$.

nonsignificant. However, among measures that were derived from the collaborative play session, at both time points large positive associations emerged between mother and child exploratory play and between mother and child symbolic play: Mothers who demonstrated and solicited more exploratory play had children who engaged in more exploratory play, and mothers who demonstrated and solicited more symbolic play had children who engaged in more symbolic play. No correlations differed between 13 and 20 months.

Predictive. Partial correlations between mother and child play across time, controlling maternal education and hours of employment as well as concurrent partner 
play, were also examined. Child solitary and collaborative exploratory and symbolic play at 13 months were not associated with maternal exploratory and symbolic play at 20 months, $r \mathrm{~s}=-.21-.22, n s$. However, maternal exploratory demonstrations and symbolic solicitations at 13 months were related to child collaborative exploratory and symbolic play at 20 months when controlling for maternal education, hours of employment, and 20 month play (see Table 3). In general, maternal exploratory demonstrations and symbolic solicitations at 13 months had lasting effects on child collaborative play 7 months later, over and above the concurrent maternal exploratory demonstrations and symbolic solicitations, respectively.

\section{CONCLUSIONS}

The present prospective longitudinal study examined individual differences, developmental changes, and mother-child associations in South Korean child and mother exploratory and symbolic play when children were 13 and 20 months. The application of a common coding system to child and mother play permitted empirical investigation of behavioral parallels between children and their mothers. Summarizing, children engage in both exploratory and symbolic object play, but as they get older they engage in more symbolic play (developmental discontinuity). Despite this increase in symbolic play from 13 to 20 months, mothers in our study demonstrated less symbolic play to their 20-montholds than to their 13-month-olds. Perhaps mothers demonstrated less symbolic play because their children were already exhibiting symbolic behaviors and therefore did not need additional guidance. Child exploratory play, maternal demonstrations of exploratory play, and maternal solicitations of symbolic play were all continuous across time. Still, children participated in more symbolic play and less exploratory play when with their mothers than when they played alone. Child collaborative play is normally more sustained, more complex, and more diverse than is child solitary play. Child solitary symbolic play was correlated with child collaborative symbolic play, indicating that children who engaged in more symbolic play while alone also engaged in more symbolic play while playing with their mothers. Only child solitary symbolic play was stable from 13 to 20 months. All other child and mother play was unstable. At both ages, mothers who demonstrated and solicited more exploratory play had children who engaged in more exploratory play, and mothers who demonstrated and solicited more symbolic play had children who engaged in more symbolic play in the collaborative play session. These results point to mother-infant correspondence and attunement in South Korea. Likewise, 13-month maternal play predicted 20-month child collaborative play even controlling for 20-month maternal play. In general, maternal demonstrations and solicitations at 13 months exerted lasting effects on child collaborative play 7 months later, over and above maternal concurrent demonstrations and solicitations. Mothers solicited more exploratory play from their sons at 13 months and more exploratory play from their daughters at 20 months.

Korean mothers today tend to think that play offers the chance to communicate and 
to interact with their children (Lee, 2000; Moon, 1996). South Koreans, like Asian mothers generally, have high expectations for their children's achievements, and they believe that they play an important role in promoting their children's success. Moreover, in Asian cultures, independent exploration by an individual is not valued so highly as it is in Western cultures. These findings can be related to a study that compared 13-month play in mothers and infants in another east Asian setting, Japan (Tamis-LeMonda, Bornstein, Cyphers, Toda, \& Ogino, 1992). Japanese mothers also encouraged their infants in symbolic play which was interactional and other-oriented. For example, Japanese mothers demonstrated symbolic play to their children, such as feeding or kissing a doll. They encouraged interdependent play in their children and emphasized social relationships. Emphases on these characteristics of play are expected in collectivistic and sociocentric cultures like South Korea and Japan.

The overarching purpose of this longitudinal study was to investigate development of play in Korean children and mothers. Longitudinal studies of development are rare in Korea. We observed natural play interactions between mothers and infants in the home setting twice across the child's second year. This study confirms that maternal play relates to child play. Future studies might investigate children's play development in other samples of Korean society and relations between language and play representational systems.

\section{REFERENCES}

Bae, K., Sung, H., Lee, J., Kwak, K, Chang-Song, Y., \& Sim, H. 2004. Developmental change of the pretend play and imitation in infants and toddlers. The Korean Journal of Human Development, 11, 83-99.

Belsky, J., \& Most, R. K. 1981. From exploration to play: A cross-sectional study of infant free play behavior. Developmental Psychology, 17, 630-639.

Bornstein, M. H. 1980. Cross cultural developmental psychology. In M. H. Bornstein (Ed.), Comparative methods in psychology (pp. 231-281). Hillsdale, NJ: Erlbaum.

Bornstein, M. H. (Ed.). 1991. Cultural approaches to parenting. Hillsdale, NJ: Erlbaum.

Bornstein, M. H. 1995. Form and function: Implications for studies of culture and human development. Culture \& Psychology, 1, 123-137.

Bornstein, M. H. 2006. On the significance of social relationships in the development of children's earliest symbolic play: An ecological perspective. In A. Gönçü \& S. Gaskins (Eds.), Play and development: Evolutionary, sociocultural and functional perspectives (pp. 101-129). Mahwah, NJ: Erlbaum.

Bornstein, M. H., Brown, E. M., \& Slater, A. M. 1996. Patterns of stability and continuity in attention across early infancy. Journal of Reproductive and Infant Psychology, 14, 195-206.

Bornstein, M. H., Hahn, C.-S., Suwalsky, J. T. D., \& Haynes, O. M. 2003. Socioeconomic status, parenting, and child development: The Hollingshead Four-Factor Index of Social Status and the Socioeconomic Index of Occupations. In M. H. Bornstein \& R. H. Bradley (Eds.), Socioeconomic status, parenting, and child development. (pp. 29-82). Mahwah, NJ: Erlbaum.

Bornstein, M. H., Haynes, O. M., Legler, J. M., O’Reilly, A. W., \& Painter, K. M. 1997. Symbolic play in childhood: Interpersonal and environmental context and stability. Infant Behavior and Development, 20, 197-207.

Bornstein, M. H., Haynes, O. M., O’Reilly, A. W., \& Painter, K. 1996. Solitary and collaborative pretense play in early childhood: Sources of individual variation in the development of representational competence. Child Development, 67, 2910-2929.

Bornstein, M. H., \& O'Reilly, A. W. (Eds.). 1993. The role of play in the development of thought. San 
Francisco: Jossey-Bass.

Caldera, Y. M., Huston, A. C., \& O’Brien, M. 1989. Social interactions and play patterns of parents and toddlers with feminine, masculine, and neutral toys. Child Development, 60, 70-76.

Choi, S. C., Kim, U., \& Choi, S. H. 1993. Korean culture and collective representation. In Kim, U., \& Berry, J. W. (Eds.), Indigenous psychologies: Experience and research in cultural context (pp. 193-210). Newbury Park, CA: Sage.

Damast, A., Tamis-LeMonda, S., \& Bornstein, M. 1996. Mother-child play: Sequential interaction and the relation between maternal belief and behaviors. Child Development, 67, 1752-1766.

Dunn, J., \& Wooding, C. 1977. Play in the home and its implications for learning. In B. Tizard \& D. Harvey (Eds.), The biology of play (pp. 45-58). Philadelphia: Lippincott.

Edwards, C. P., \& Liu, W. 2002. Parenting toddlers. In M. H. Bornstein (Ed.), Handbook of parenting: Vol. 1. Children and parenting ( $2^{\text {nd }}$ ed., pp. 45-71). Mahwah, NJ: Erlbaum.

Fagot, B. I. 1995. Parenting boys and girls. In M. H. Bornstein (Ed.), Handbook of parenting: Vol. 1 . Children and parenting (pp. 163-183). Mahwah, NJ: Erlbaum.

Fiese, B. H. 1990. Playful relationships: A contextual analysis of mother-toddler interaction and symbolic play. Child Development, 61, 1648-1656.

Hollingshead, A. B. 1975. The four factor index of social status. Unpublished manuscript, Yale University.

Kennedy, S., Scheirer, J., \& Rogers, A. 1984. The price of success: Our monocultural science. American Psychologist, 39, 996-997.

Kim, H. 1995. Maternal belief about child-rearing in Korea and the United States. Child Education Study, 15, 5-22.

Kim, U., \& Park, Y. S. 2003. An indigenous analysis of success attribution: Comparison of Korean students and adults. In K. Yang, K. Hwang, P. D., Pedersen, \& I. Daibo (Eds.), Progress in Asian social psychology: Conceptual and empirical contributions (pp. 171-189). Westport, CT: Praeger Publishers.

Kim, Y., \& Lee, J. 2003. Symbolic levels of early pretense and representational thinking. The Korean Journal of Child Studies, 24, 1-14.

Leaper, C. 2002. Parenting girls and boys. In M. H. Bornstein (Ed.), Handbook of Parenting: Vol. 1. Children and Parenting ( $2^{\text {nd }}$ ed., pp. 189-225). Mahwah, NJ: Erlbaum.

Lee, S. 2000. Preschoolers' daily activities and self-direction: The US and Korea. Korean Journal of Psychology: Development, 13, 35-48.

Maday, B C., \& Szalay, L. B. 1976. Psychological correlates of family socialization in the United States and Korea. In T. Williams (Ed.), Psychological anthropology. The Hague: Mouton.

McCune-Nicolich, L., \& Fenson, L. 1984. Methodological issues in studying early pretend play. In T. D. Yawkey \& A. D. Pelligrini (Eds.), Child's play: Developmental and applied (pp. 81-124). Hillsdale, NJ: Erlbaum.

Min, P. G. 1995. Asian Americans: Contemporary trends and issues. Newbury Park, CA: Sage.

Moghaddam, F. M. 1987. Psychology in three worlds. American Psychologist, 42, 912-920.

Moon, H. 1996. A study on the developmental change in pretend play from 20 to 35 months of age. Unpublished Dissertation, Sookmyung Womens University, Seoul.

O'Connell, B., \& Bretherton, I. 1984. Toddler's play, alone and with mother: The role of maternal guidance. In I. Bretherton (Ed.), Symbolic play: The development of social understanding (pp. 337-368). Orlando, FL: Academic.

Park, I. H., \& Cho, L.-J. 1995. Confucianism and the Korean family. Journal of Comparative Family Studies, 26, 117-134.

Rubin, K. H., Fein, G. G., \& Vandenberg, B. 1983. Play. In E. M. Hetherington (Ed.), P. H. Mussen (Series Ed.), Handbook of child psychology: Vol. 4. Socialization, personality, and social development (pp. 693-774). New York: Wiley.

Russell, R. 1984. Psychology in its world context. American Psychologist, 39, 1017-1025.

Stevenson, M. B., Leavitt, L. A., Roach, M. A., Chapman, R. S., \& Miller, J. F. 1986. Mothers' speech to their 1-year-old infants in home and laboratory settings. Journal of Psycholinguistic Research, 15, 451-461.

Tamis-LeMonda, C. S., \& Bornstein, M. H. 1996. Variation in children's exploratory, nonsymbolic, and symbolic play: An explanatory multidimensional framework. In C. R. Rovee-Collier \& L. P. Lipsitt 
(Eds.), Advances in infancy research (Vol. 10, pp. 37-78). Norwood, NJ: Ablex.

Tamis-LeMonda, C., Bornstein, M., Cyphers, L., Toda, S., \& Ogino, M. 1992. Language and play at one year: A comparison of toddlers and mothers in the United States and Japan. International Journal of Behavior Development, 15, 19-42.

Tamis-LeMonda, C. S., Chen, L. A., \& Bornstein, M. H. 1998. Mothers' knowledge about children's play and language development: Short-term stability and interrelations. Developmental Psychology, 34, 115-124.

Tamis-LeMonda, C. S., Uñgiris, I. ћ, \& Bornstein, M. H. 2002. Play in Parent-Child Interactions. In M. H. Bornstein (Ed.), Handbook of parenting: Vol. 5. Practical Parenting ( $2^{\text {nd }}$ ed., pp. 221-241). Mahwah, NJ: Erlbaum.

Tukey, V. W. 1977. Exploratory data analysis. Menlo Park, CA: Addison Wesley.

Užgiris, I. C., Benson, J. B., Kruper, J. C., \& Vasek, M. E. 1989. Contextual influences on imitative interactions between mothers and infants. In J. Lockman \& N. L. Hazen (Eds.), Action in social context: Perspectives on early development (pp. 103-127). New York: Plenum.

Užgiris, I. C., \& Raeff, C. 1995. Play in parent-child interactions. In M. H. Bornstein (Ed.), Handbook of parenting: Vol. 4. Applied and Practical Parenting (pp. 353-376). Mahwah, NJ: Erlbaum.

Vibbert, M., \& Bornstein, M. H. 1989. Specific associations between domains of mother-child interaction and toddler referential language and pretense play. Infant Behavior and Development, 12, 163-184.

Vygotsky, L. 1978. Mind in society. Cambridge, MA: Harvard University Press.

(Manuscript received September 7, 2006; Revision accepted June 19, 2007) 